\title{
Dreadlocks and Mental Disease An old argument and an early epidemiological study (1843)
}

\author{
H. FÖRSTL and H. ELLIGER
}

Enigmatic disease concepts are notoriously difficult to refute. The history of 'trichoma' illustrates the spectacular rise and silent vanishing of an obscure ailment once thought to be responsible for a large proportion of mental disturbances.

Dreadlocks (convolutio et contricatio capillorum firmissima) formed the diagnostic sign of a disease called trichoma, plica polonica (Latin), kottun (Polish) and Weichsel- or Hexenzopf ('witchplait'; German). This illness had been prevalent in Poland during the late middle ages and Renaissance (Cromerius, 1558). Staringelius (1599), rector of the University of Zamosc, was the first Polish physician who wrote about this disease. Schlegel (1806) reviewed the literature of the following 200 years and listed 136 papers, dissertations and monographs from different authors. The number of publications increased steadily until in 1843 Beschorner, director of the first asylum in Poland, published a large population-based study and could not substantiate the disease concept. This led to an immediate cessation of publications on the matter.

\section{Publications before 1843}

The symptoms and signs of trichoma were described as protean, a 'chameleon' with hardly two cases resembling one another (Matuszynski, 1832). The premonitory stage was believed to develop over a period of from six hours to several months with headaches, increased sensitivity to light, sound and touch, vertigo, tinnitus, pain in the eyes, ears, bones and joints, disturbances of sleep and appetite (pica), constipation or diarrhoea, etc. If the trichoma was cut off during this first phase, the unhealthy substances or 'miasmas' were feared to attack other organs, causing melancholic, hypochondriacal, hysterical and epileptic states or encephalitis and meningitis. Fevers heralded the second stage of illness with a fully developed trichoma, which could then fall off spontaneously or be removed without a major risk for life or mental sanity (Wolfram, 1804; Schlegel, 1806).

Different types of immature and mature, real or false, dry and humid trichoma were distinguished and it was accepted that similar phenomena could occur in dogs, oxen, sheep, wolves and foxes
(Chromy, 1813). Even though the existence of this disease was not questioned, its nature was a subject of controversy. A hereditary transmission was proposed, because the real trichoma allegedly affected Polish and Jewish men after the age of six, but not women or foreigners (Schlegel, 1806). Other authors favoured the contagious, infectious paradigm and thought that trichoma was a modified form of lepra, or syphilis or of another venereal 'miasma' (Frank, 1788; Wolfram, 1804). A lack of cleanliness, and the obstruction of fine tubules in the hair due either to the constant use of fur hats or to shaving of the head, were discussed as modifying influences (Schlegel, 1806; Chromy, 1813). Matuszynski (1832) suggested that trichoma was the local and endemic crisis of a variety of acute or chronic diseases.

Schlegel (1806) wrote that trichoma had a lethality of $5 \%$, leaving $45 \%$ of the affected crippled and with $50 \%$ making a full recovery. He felt that trichoma was the true cause of up to 32000 of 55000 deaths per year. The estimated prevalence was $1: 10$ to $1: 30$ (de la Fontaine, 1792; Schlegel, 1806).

\section{Beschorner's epidemiological study}

Beschorner was the director of the first asylum in Poland and thought that a thorough scientific study of this matter was urgently needed, because according to public and medical opinion - there was a close causal relationship between trichoma and mental illness ('Irresein'). He used data which had been solicited by Minutoli, the governor and police president of Posen in 1842.

5327 cases of trichoma were identified, yielding a prevalence of $1: 231$ in a total population of 1233850 in the county of Posen. Beschorner admitted that cases may have been missed and that the true prevalence was probably slightly higher, though ten times as great seemed most unlikely.

2460 patients were male and 2687 were female, and therefore the male preponderance and the transmission pattern suggested earlier could not be supported (de la Fontaine, 1792; Schlegel, 1806).

Seventeen per cent of the reported cases were five years old or younger. This was considered as an argument against the venereal nature of trichoma and the opinion that trichoma would only develop after 
the age of six was refuted. Eleven per cent of the cases were over 60 years old, corresponding to $26 \%$ of individuals in this age group. Only $9 \%$ of the cases were children and adolescents between 10 and 20 years. Beschorner hypothesised that a greater cleanliness in this age group might contribute to this effect.

Trichoma was more frequent in Catholics $(1: 170)$ than in Jews $(1: 264)$ or Protestants $(1: 849)$. Beschorner found that this was related to the ethnic background, with the Slavic [Catholic] population being more frequently affected $(1: 171)$ than the Jewish $(1: 264)$ or German [Lutheran] people $(1: 730)$, and to the social status, with $90 \%$ of all reported cases coming from the lowest socioeconomic class.

Beschorner questioned the diagnostic significance of trichoma, because in $20 \%$ of all individuals with this sign, no other signs or symptoms of illness were found.

He questioned the idea of heredity or familiarity, because $80 \%$ of the cases were sporadic. If more than one case per family was found, there was often excess morbidity from other illnesses and the majority of family members would still be unaffected.

Beschorner used 12 physically healthy chronic psychiatric in-patients to prove that trichoma was simply caused by the appropriate external conditions. The patients were not allowed to comb or brush their hair and had to wear tight caps. All of five women and two of seven men developed trichoma. He went one step beyond and inoculated specimens from trichoma patients into the scalp of other patients and could not observe a faster development of trichoma in the inoculated patients (an early example of the abuse of psychiatric in-patients for research purposes).

He concluded that trichoma was not a disease sui generis and that it did not exert a significant effect on other illnesses. His results were immediately accepted by the scientific public (e.g. Rohnert, 1844).

\section{Comment}

Trichoma is one example of folk mythology intruding into medical science. In spite of its obscure nature, its presumed importance seemed to grow with an increasing number of publications about this topic. Most of the literature on trichoma is highly repetitive. A large number of dissertations simply combined previous publications without introducing any original thought and data. The concepts became more complex and confused. Trichoma was not only the external sign, but also the disease itself and also its remedy. Mental illness was its cause and its consequence.

Empirical data were necessary to clarify the most fundamental issues regarding trichoma. With the introduction of the simple statistical methods of his time, Beschorner put an end to useless academic debates. Beschorner demonstrated the insignificance of the presumed relationship between an individual symptom - the dreadlock - and its surmised causes and accompanying features, devaluating rather than falsifying the trichoma concept. The availability of novel methods or insights into medical science may lead to similar revolutions, with concepts sinking into oblivion rather than clashing with new paradigms (Kuhn, 1962).

\section{Acknowledgement}

The preparation of the manuscript was supported by an $H$. \& $\mathrm{L}$. Schilling professorship to H.F.

\section{References}

Beschorner, F. (1843) Der Weichselzopf. Nach statistischen und physiologischen Beziehungen dargestellt. Breslau: F. Hirt.

Снгому, T. E. (1813) Neueste Ansichten des Weichselzopfes in seiner Grundursache. Freyberg: Craz \& Gerlach.

Cromerius, M. (1558) Polonia s. de Origine et Rebus Gestis Polonorum. Libr. XXX. Basle.

DE LA FONTAINE, S. (1792) Chirurgisch-medicinische Abhandlungen Polen betreffend. Breslau.

Frank, P. J. (1788) System einer vollständigen medicinischen Polizey. IV. Vienna: Trattner.

KUнN, T. S. (1962) The structure of scientific revolutions. Foundations of the Unity of Science, 2, (2).

Matuszynskı, J. (1832) Uber die Natur und Behandlung des Weichselzopfes. Univ. Tübingen (Diss.): Osiander.

Rohnert, C. F. A. (1844) De plica Polonica. Gryphia: F. G. Kunike.

Schlegel, J. F. A. (1806) Uber die Ursachen des Weichselzopfes der Menschen und Thiere. Jena: J. C. G. Göpferdt.

Staringelus, L. (1599) Epistola ad Academia Paduanam de Plica. WolfraM, J. G. (1804) Versuch über die höchstwahrscheinlichen Ursachen und Entstehung des Weichselzopfes nebst einer sicheren Heilung desselben. Breslau: W. G. Korn.

\section{H. Förstl, MD, Hanna Elliger, Central Institute of Mental Health, Mannheim}

Correspondence: Dr H. Förstl, Central Institute of Mental Health, J5, 68159 Mannheim, Germany

(First received 3 October 1994, final revision 2 November 1994, accepted 8 December 1994) 